\title{
Sudden infant death syndrome and psychiatric
} disorders

\author{
LOUISE MICHELE HOWARD and SIMON HANNAM
}

Sudden infant death syndrome (SIDS) is the most common type of post-neonatal death in infants aged under 1 year, and is defined as the sudden death of a baby that is unexpected from the baby's history and unexplained by a thorough post-mortem examination (Hunt, 1992). Current aetiological theories of SIDS involve multifactorial models, which include the prone sleeping position, socio-economic deprivation, smoking in either parent, and prematurity as major risk factors. The incidence of SIDS in the UK has fallen since the 'back to sleep' campaign (initiated in 1992) and stood at 0.56 per 1000 live births in 1998. Since the 'back to sleep' campaign began there has been a change in the relative importance of risk factors, with single marital status, ethnicity and initiation of prenatal care in the third trimester becoming more significant (Paris et al, 2001), and psychiatric disorders have also emerged recently as possible risk factors (Mitchell et al, 1992; Bennedsen et al, 2001a; Sanderson et al, 2002).

\section{POSTNATAL DEPRESSION AND SIDS}

Postnatal depression is consistently found in $12-13 \%$ of mothers in epidemiological surveys (O’Hara \& Swain, 1996) and is therefore one of the most common complications of childbearing. Two prospective studies have reported an association between postnatal depression and SIDS (Mitchell et al, 1992; Sanderson et al, 2002), with an odds ratio of around 3 in both studies. If postnatal depression is a causal factor for SIDS, then a significant proportion of SIDS is potentially attributable to postnatal depression. However, it is unclear whether the reported association is causal, as both studies suffered from a high rate of missing data, used a screening self-report questionnaire as a measure of possible depression (the Edinburgh
Postnatal Depression Scale; Cox et al, 1987) rather than diagnosed cases of depression, and had small numbers of SIDS cases (33 and 26 respectively). Nevertheless, after controlling for socio-economic status and smoking, an independent association between postnatal depression and SIDS remained.

Postnatal depression is associated with deficits in maternal-infant interactions: for example, mothers with postnatal depression have been observed to be less responsive to their infant's behaviour (Field et al, 1985). Infants who die from SIDS have symptoms in the few days prior to death (Stanton et al, 1978), and it is possible that mothers with depression are less attuned to their infant's health status and well-being and are less able to respond appropriately to any changes in the infant. Alternatively, SIDS babies might be less physiologically mature and more likely to induce depression in the mothers; this theory is supported by the finding that postnatal depression is associated with infants who are irritable (Murray et al, 1996).

\section{SCHIZOPHRENIA AND SIDS}

A much larger study using data from the Danish Psychiatric Register and the Danish Medical Birth Register has reported a relative risk of 5 for SIDS in the children of women with schizophrenia after adjustment for birthweight and gestational age (Bennedsen et al, 2001a). Unlike in the studies investigating SIDS and postnatal depression there was no adjustment for socio-economic status or smoking, which the authors acknowledge might have led to residual confounding. The children of women with schizophrenia tend to have a lower Apgar score (Bennedsen et al, $2001 b$ ) and several studies have reported that women with schizophrenia have a higher incidence of stillbirths and neonatal deaths (Rieder et al, 1975; Wrede et al,
1984), although this has not been a consistent finding (Bennedsen et al, 2001a). These reports suggest that the children of women with schizophrenia are in poor condition at birth, which may increase their risk of subsequent death. Mothers with schizophrenia may also have difficulty in taking care of their children and may have an inadequate reaction to illness in their children, although there was no evidence of this in a recent study of the medical outcome of infants of mothers with a history of psychotic disorders (Howard et al, 2003).

\section{NON-ACCIDENTAL DEATHS}

It is possible that some deaths recorded as SIDS are disguised homicides, as it can be impossible to distinguish between SIDS and death due to imposed airway obstruction (Green, 2001); however, it is not known what proportion of SIDS deaths are non-accidental (Meadow, 1999). There is no evidence of increased rates of nonaccidental injury in children of mothers with severe mental illness, but there may be an increased risk of physical abuse of children by mothers with depression and anxiety, particularly when associated with personality problems and young age (Oates, 1997).

\section{OTHER RISK FACTORS}

Substance misuse is associated with an increased risk of infant death, including SIDS (Confidential Enquiry into Stillbirths and Deaths in Infancy, 2000) and may be significant in its own right, in addition to comorbidity complicating other psychiatric disorders. The association between SIDS and psychiatric disorders may also be explained by other residual confounders, such as smoking, psychopharmacological treatment or risk factors in the father. Mothers with major psychiatric disorders may find it particularly difficult to control their infant's smoke exposure from their own smoking or that of their partner. In addition, infants may appear to be more comfortable or sleep better in a prone position, and it is conceivable that stressed mothers place their babies prone for better sleep. Mothers with psychiatric disorders may therefore find it more difficult to modify known risk factors. This was found in mothers from a relatively deprived area in Cardiff who were less likely to place their babies on their backs and were more likely 
to smoke than mothers in a more affluent area, despite a high awareness of SIDS and risk-reducing measures in both areas (Shrivastava et al, 1997). Conroy \& Marks (2003) found psychological vulnerability, rather than deprivation, was associated with infant care practices known to be risk factors for SIDS.

Alternatively, women with major psychiatric disorders might not have been given advice on reducing risk factors for SIDS because health professionals were too preoccupied with the mother's mental state. There is some evidence that certain groups in the USA have not received or recognised the importance of the 'back to sleep' campaign (Brouillette, 2001), but this has not been investigated for women with psychiatric disorders.

\section{CONCLUSIONS}

The studies linking SIDS and psychiatric disorders do not provide clear evidence for an association between the two, and research is needed to investigate this further. However, SIDS is likely to represent a heterogeneous group of conditions, some - but not necessarily all - of which may be associated with parental psychological and behavioural factors through multiple pathways. It is therefore important that childbearing women with psychiatric disorders are helped to decrease potential risk factors for SIDS - for example, encouraged to stop smoking in pregnancy, and if they cannot stop smoking, to subsequently reduce the infant's smoke exposure. Mothers must also be informed of the importance of putting their baby on its back to sleep. Close liaison between all health care professionals involved in the care of mothers and babies is essential to ensure that these patients receive optimal antenatal and postnatal care. However, SIDS remains a poorly understood condition and it is not known whether there are any specific interventions that could be helpful in reducing these deaths in the infants of mothers with psychiatric disorders. Most importantly, mothers who do experience a SIDS death should not feel

LOUISE MICHELE HOWARD, MRCPsych, Institute of Psychiatry, London; SIMON HANNAM, FRCPCH, King's College Hospital, London, UK

Correspondence: Dr Louise Howard, Health Services Research Department, Institute of Psychiatry, De Crespigny Park, Denmark Hill, London SE5 8AF, UK. Tel: 0207848 0735; fax 0207277 I462; e-mail: I. howard@iop.kcl.ac.uk

(First received 16 April 2002, final revision 6 August 2002, accepted 7 August 2002)

blamed for this tragedy, and if they are already psychologically vulnerable, they should be offered appropriate support from psychiatric services, in addition to support from paediatricians and the primary care team.

\section{DECLARATION OF INTEREST}

None.

\section{REFERENCES}

Bennedsen, B. E., Mortensen, P. B., Olesen, A. V., et al (200la) Congenital malformations, stillbirth and infant deaths among children of women with schizophrenia. Archives of General Psychiatry, 58, 674-679.

_ , _ , _ , et al (200lb) Obstetric complications in women with schizophrenia. Schizophrenia Research, $\mathbf{4 7}$ 167-175.

Brouillette, R.T. (200I) Risk factors for SIDS as targets for public health campaigns. Journal of Pediatrics, $\mathbf{1 3 9}$ 759-761.

\section{Confidential Enquiry into Stillbirths and Deaths in} Infancy (2000) Seventh Annual Report. London: Maternal and Child Health Research Consortium.

\section{Conroy, S. \& Marks, M. N. (2003) Maternal}

psychological vulnerability and early infant care in a sample of materially disadvantaged women. Journal of Reproductive and Infant Psychology, in press.

Cox, J. L., Holden, J. M. \& Sagovsky, R. (1987)

Detection of postnatal depression. Development of the 10-item Edinburgh Postnatal Depression Scale. British Journal of Psychiatry, I50, 782-786.

Field, T., Sandberg, D., Garcia, M., et al (1985)

Pregnancy problems, postpartum depression and early mother infant interactions. Developmental Psychology, 2I II52-II56.

Green, M. A. (200I) Time to put 'cot death' to bed? BMJ, 319, 697-698.

Howard, L. M., Goss, C., Leese, M., et al (2003) Medical outcome of pregnancy in women with psychotic disorders and their infants in the first year after birth. British Journal of Psychiatry, in press.
Hunt, C. E. (1992) Sudden infant death syndrome. In Respiratory Control Disorders in Infants and Children (eds R. C. Beckerman, R. T. Brouillete \& C. E. Hunt) Baltimore, MD: Williams \& Wilkins.

Meadow, R. (1999) Unnatural sudden infant death. Archives of Disease in Childhood, 80, 7-14.

Mitchell, E. A., Thompson, J. D., Stewart, A.W., et al (1992) Postnatal depression and SIDS: a prospective study. Journal of Paediatrics and Child Health, 28 (suppl. I), 13-16.

Murray, L., Stanley, C., Hooper, R., et al (1996) The role of infant factors in postnatal depression and mother infant interactions. Developmental Medicine and Child Neurology, 38, 109-119.

Oates, M. (1997) Patients as parents: the risk to children. British Journal of Psychiatry, 170 (suppl. 32), 22-27.

O'Hara, M. \& Swain, A. M. (1996) Rates and risk of postpartum depression - a meta-analysis. International Review of Psychiatry, 8, 37-54

Paris, C. A., Remler, R. \& Daling, J. R. (200I) Risk factors for sudden infant death syndrome: changes associated with sleep position recommendations. Journal of Pediatrics, I39, 77I-777.

Rieder, R. C., Rosenthal, D., Wender, P., et al (1975)

The offspring of schizophrenics: fetal and neonatal deaths. Archives of General Psychiatry, 32, 200-2II.

Sanderson, C. A., Cowden, B., Hall, D. M. B., et a (2002) Is postnatal depression a risk factor for sudden infant death? British Journal of General Practice, 52, 636-640.

Shrivastava, A., Davis, D. \& Davis, D. P. (1997) SIDS: parental awareness and infant care practices in contrasting socio-economic areas in Cardiff. Archives of Disease in Childhood, 77, 52-53.

Stanton, A. N., Downham, M. A., Oakely, J. R., et a (1978) Terminal symptoms in children dying suddenly and unexpectedly at home. Preliminary report of the DHSS multicentre study of postneonatal mortality. BMJ, 2. 1249-1251.

Wrede, G., Mednick, S. A., Huttunen, M. O., et al (1984) Pregnancy and delivery complications in the births of an unselected series of Finnish children with schizophrenic mothers. In Children at Risk for Schizophrenia (eds N. F.Watt, E. J. Anthony, L. C.Wynn, et al), pp. 515-525. London: Cambridge University Press. 